\title{
Force-displacement relations of bolted timber joints with slotted-in steel plates parallel to the grain
}

\author{
Yingyang Liu* ${ }^{*}$, Yixuan Wang, Yiming Zhang, Minghui Chen and Xizhe Nie
}

\begin{abstract}
To study the force-displacement relations of bolted timber joints with slotted-in steel plates, we performed a monotonic loading test parallel to the grain on 24 specimens. The influences of the bolt diameter, timber thickness, and their ratio were considered. As shown by the test results, the joints had a high deformation capacity and experienced a linear stage, a stiffness degradation stage, a yield plateau stage, and a failure stage during loading. Based on the curve fitting and parameter identification, the force-displacement relations of the joints were summarized in a mechanical model with two parameters, i.e., the bearing capacity and the elastic stiffness. Based on theoretical analysis, we proposed a theoretical calculation formula for the bearing capacity and elastic stiffness of the joints. Finally, we calculated the force-displacement relation curves of bolted timber joints with slotted-in steel plates using the mechanical model and the theoretical formula. The calculated curves fitted well with the experimental curves.
\end{abstract}

Keywords: Timber structure, Bolted joint, Experimental study, Theoretical analysis, Mechanical model

\section{Introduction}

Metallic connectors are commonly used in modern timber engineering. They provide reliable connections while enhancing structural ductility. Characterized by clear force transmission and simple installation, bolted connections have been extensively used (Fig. 1). Joints that use concealed slotted-in steel plate connection members are architecturally favorable, so this is a commonly used connection technique.

The European Yield Model (EYM) [1] has been widely used in the calculation and analysis of bolted timber connections. The EYM assumes that the bearing performance of wood underneath steel dowels (in this paper, "dowel" refers to "steel dowel") and the bending performance of bolts jointly determine the bearing capacity of a connection. The related contents of the current US National Design Specifications (NDS) [2], Canada CSA O86 [3], and Eurocode 5 [4] have been developed on the

*Correspondence: liuyingyang5687@qq.com

School of Civil Engineering, Zhengzhou University, No. 100 Science

Avenue, Zhengzhou 450001, China basis of the EYM. Sawata et al. [5, 6] performed a dowel bearing test of wood and a shear test for bolted joints and then applied a theoretical analysis using the EYM, and the theoretical values fitted well with the experimental values. Dorn et al. [7] systematically studied the mechanical properties of bolted timber joints, including the timber density, bolt slenderness, friction, geometric arrangement, and reinforcement measures, and analyzed and discussed the stages of the force-displacement curve throughout the process. Jorissen [8] and Xu et al. [9] took into account the brittle failure of timber, assuming that the connectors did not fully reach the plastic state during failure, carried out a theoretical analysis and numerical simulations based on the fracture mechanics, and proposed the related bearing capacity theoretical formula.

In the design of timber engineering, the hypothesis of hinged joints is mostly used. Consequently, the above studies only focused on the bearing capacity of the joint. However, in practice, the bolt group joints show semirigidness and undergo a certain bending moment and may crack as a result, which influences the performance of the structure $[10,11]$. For the determination of the 


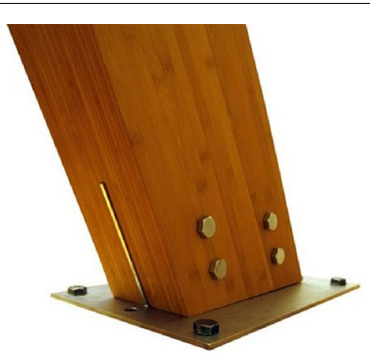

Fig. 1 Bolted timber joints with slotted-in steel plates

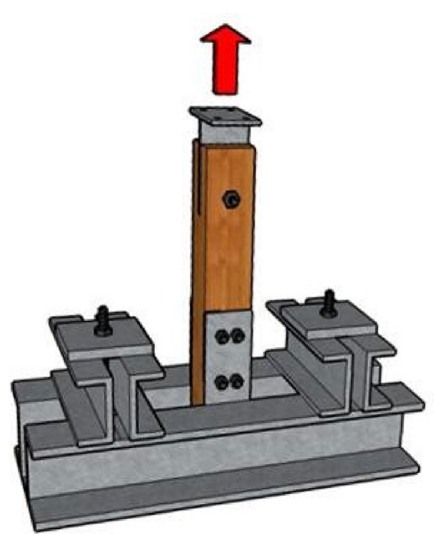

Fig. 2 Test schematic of the mechanical properties of the bolted timber joints with slotted-in steel plates parallel to the grain

semirigidness of a joint, it is necessary to probe the stiffness of a single-bolt joint and the process-wide forcedisplacement relations $[12,13]$. Therefore, the objectives of this study were to (1) carry out mechanical property testing parallel to the grain by taking bolted timber joints with slotted-in steel plates as the study object, (2) construct a mechanical model for the process-wide forcedisplacement relations, (3) derive the theoretical formula for the bearing capacity and stiffness, and (4) provide a theoretical basis for further application and promotion of such joints.

\section{The mechanical property testing of bolted timber joints with slotted-in steel plates Test overview}

We designed 24 bolted timber joints with slotted-in steel plates for mechanical property testing parallel to the grain (Fig. 2). The lower portion of each specimen was the anchored end, and the upper portion was the joint of interest. The specimens were designed with different values for the bolt diameter $(d)$, timber thickness $(l)$, and slenderness $(l / d)$ to study their influences. In addition, the specimens had heights of $700 \mathrm{~mm}$ and widths of
$105 \mathrm{~mm}$. The design details of the specimen are shown in Fig. 3, and the specimen types are shown in Table 1.

The specimen timber was glulam that was fabricated by Suzhou Crownhomes Co., Ltd., with Grade II SprucePine-Fir dimensional lumber imported from Canada as the raw material. Common bolts with a strength grade of 6.8 and a tensile strength of $600 \mathrm{MPa}$ were used. The 10 -mm-thick steel plate was made of Q235 steel.

The specimen loading test was performed using a MAS-100 hydraulic servo actuator from Hangzhou POPWIL Electromechanical Control Engineering Co., Ltd., in the form of monotonic loading with displacement control at a loading rate of $1.5 \mathrm{~mm} / \mathrm{min}$. After preloading, continuous loading was performed on each specimen (Fig. 4) until the specimen apparently failed or the load was reduced to $80 \%$ of the maximum load. Four displacement transducers were used to obtain the relative displacement between the timber and the bolts. D1 and D2 were attached to the steel plate to obtain its displacement (mean value of D1 and D2), while D3 and D4 were arranged in the same way to obtain the displacement of the timber.

\section{Experiment phenomena and failure patterns}

During the initial loading, the timber produced a slight crackling sound, and the bolts were basically straight. Thus, the specimen was in the linear stage. The load increased linearly with the increasing displacement. As the displacement further increased, the bolts were gradually bent, then the washer started to sink into the timber and the timber continued producing a crackling sound. At this time, the stiffness of the specimen gradually decreased, and the rate of the load increase gradually decreased. In the later loading period, the timber produced a louder sound, and some specimens produced loud sounds from the bolt fracture after yield. Then, the bearing capacity of the specimens decreased due to timber splitting failure or bolt yield, and the test was ended.

The loading tests parallel to the grain resulted in three failure patterns: (1) the timber failed due to uniform extrusion (hereinafter referred to as Pattern I); (2) plastic hinges appeared in the bolt at the contact area between the bolt and slotted-in steel plate, and the bolt outside the plastic hinge was stiff, straight, and inclined, resulting in timber extrusion, that is, one-hinge failure after bolt yield (hereinafter referred to as Pattern III); and (3) plastic hinges appeared in the bolt at the contact area between the bolt and the slotted-in steel plate and at the timber on both sides, resulting in timber extrusion between the plastic hinges, that is, two-hinge failure (hereinafter referred to as Pattern IV). The statistics of the failure patterns for the specimens are given in Table 2. 


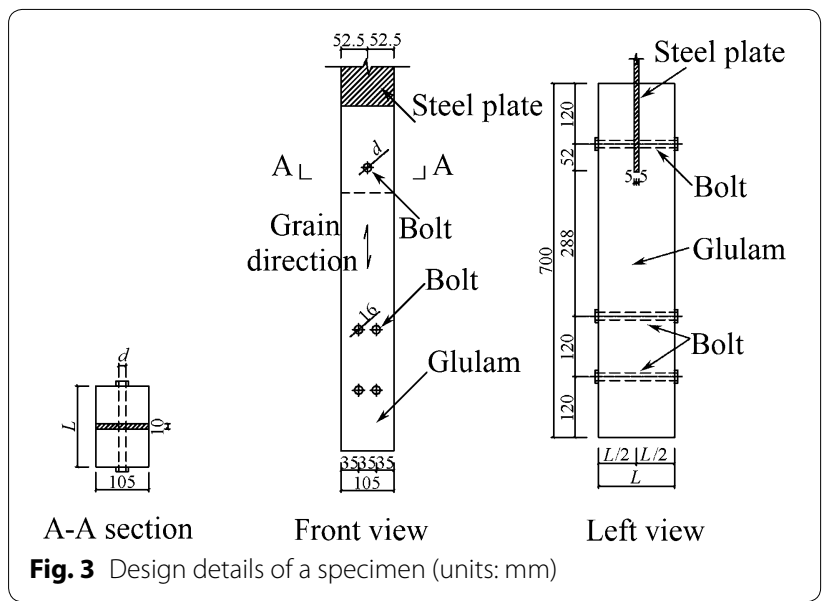

Table 2 shows that for slenderness values below 11.3, the experiment failure pattern was Pattern I; for slenderness values between 11.3 and 14.4, the experiment failure pattern was Pattern III; and for slenderness values above 14.4, the experiment failure pattern was Pattern IV. It was observed that for the specimens with the same bolt diameter $d$, as the timber thickness $l$ increased, that is, the slenderness increased, the specimen failure pattern shifted from Pattern I to Patterns III and IV. Photos of the three failure patterns are shown in Fig. 5.

\section{Experimental force-displacement curves and main mechanical property parameters}

Based on the experimental study, we plotted the force-displacement curves of the bolted timber joints with slottedin steel plates, as shown in Fig. 6. In the figure, the force is the load applied by the actuator, and the displacement is the distance that the bolt moves relative to the timber.

The following was ascertained according to Fig. 6. (1) The force-displacement curve of the single-bolted joint experienced a linear stage, a stiffness degradation stage, a yield plateau stage, and a failure stage. Some specimens exhibited a low stiffness during the initial loading stage because of the gap and initial slip between the timber and the bolt, and elastic stiffness was manifested after tight contact. (2) The specimens in the same group exhibited a good consistency in the linear stage. However, it should be noted that due to the randomness of wood, variation occurred among specimens [e.g., S-14-180(3) and S-16230(1) had greater stiffness values than the other two specimen groups]. All the specimens had an obvious yield plateau, thus manifesting a certain ductility. After a certain yield plateau, the failure patterns of some specimens showed a sudden drop in load because the joint suddenly lost bearing capacity due to timber splitting or bolt fracture.

The main mechanical property parameters of the specimens, including the bearing capacity, elastic stiffness, ultimate displacement, and ductility coefficient, are defined in Fig. 7 and were quantitatively analyzed. The bearing capacity is the peak point $P_{\mathrm{p}}$ in the forcedisplacement curve. The elastic stiffness $k_{\mathrm{e}}$ is the slope of the line connecting the $10 \%$ peak load point and the $40 \%$ peak load point [14]; this method can address the impact of the initial slip on the elastic stiffness well. The yield point is determined with the method of a $5 \%$ diameter $[15,16]$; the straight line that determines the elastic stiffness is translated to the right by a distance of $5 \%$ of the bolt diameter, and the intersection point between the translated line and the force-displacement curve is the yield point of the specimen. The yield load is $P_{y}$. The yield displacement is $\Delta_{y}$. The ultimate displacement $\Delta_{u}$ is the displacement at which the specimen exhibits obvious failure or the load decreases to $80 \%$ of the maximum load. The ductility coefficient $D$ is defined as the ratio of the ultimate displacement $\Delta_{u}$ to the yield displacement $\Delta$ $y$. The main mechanical property parameters of the specimens are shown in Table 3.

Table 3 shows the following: (1) The bearing capacity of the specimen sets was determined by the bolt diameter

Table 1 Specimen types

\begin{tabular}{|c|c|c|c|c|}
\hline Specimen series & Bolt diameter $d / \mathrm{mm}$ & Specimen thickness $/ / \mathrm{mm}$ & Slenderness I/d & $\begin{array}{l}\text { No. } \\
\text { of specimens }\end{array}$ \\
\hline S-12-105 & 12 & 105 & 8.8 & 3 \\
\hline$S-12-140$ & 12 & 140 & 11.7 & 3 \\
\hline S-14-140 & 14 & 140 & 10.0 & 3 \\
\hline S-14-180 & 14 & 180 & 12.9 & 3 \\
\hline S-14-230 & 14 & 230 & 16.4 & 3 \\
\hline S-16-140 & 16 & 140 & 8.8 & 3 \\
\hline S-16-180 & 16 & 180 & 11.3 & 3 \\
\hline S-16--230 & 16 & 230 & 14.4 & 3 \\
\hline
\end{tabular}

The specimen series is explained by taking "S-12-105" as an example, where "S" indicates that the loading direction is parallel to the grain; " 12 " represents the bolt diameter (unit: $\mathrm{mm}$ ); "105" represents the timber thickness (unit: $\mathrm{mm}$ ), the direction of which is along the bolt length, and the timber thickness is the bearing length of the steel dowel; and the slenderness represents the ratio of the timber thickness to the bolt diameter 

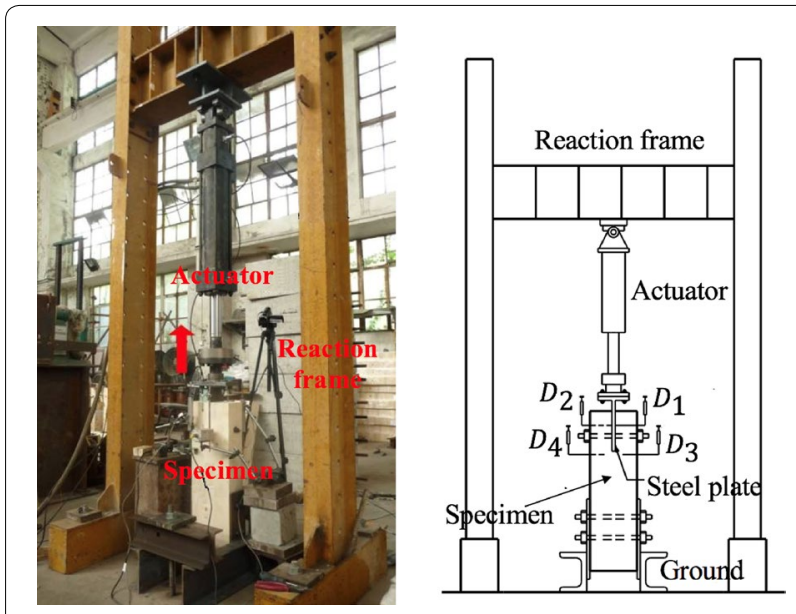

Fig. 4 Equipment for specimen loading

Table 2 Specimen failure patterns

\begin{tabular}{|c|c|c|c|c|}
\hline \multirow{2}{*}{$\begin{array}{l}\text { Specimen } \\
\text { series }\end{array}$} & \multirow[t]{2}{*}{ Slenderness } & \multicolumn{3}{|l|}{ Failure mode } \\
\hline & & Specimen 1 & Specimen 2 & Specimen 3 \\
\hline S-12-105 & 8.8 & I & । & 1 \\
\hline S-12-140 & 11.7 & III & III & III \\
\hline S-14-140 & 10.0 & I & । & । \\
\hline S-14-180 & 12.9 & III & III & III \\
\hline S-14-230 & 16.4 & IV & IV & IV \\
\hline S-16-140 & 8.8 & I & 1 & I \\
\hline S-16-180 & 11.3 & III & III & III \\
\hline S-16-230 & 14.4 & IV & IV & IV \\
\hline
\end{tabular}

The values of $P_{\mathrm{p}^{\prime}} k_{\mathrm{e}}$ and $\Delta_{u}$ in the table are the mean values of each group of specimens

and the specimen thickness, and as the bolt diameter or specimen thickness increased, the bearing capacity of the specimen increased. (2) The elastic stiffness mainly depended on the bolt diameter, and as the bolt diameter increased, the elastic stiffness increased. For specimens with the same bolt diameter, increasing the timber thickness only slightly impacted the stiffness of the joint. (3)
The bolted timber joints had a high deformation capacity, and the ductility coefficients of all specimens were above 3.0.

\section{The mechanical model of bolted timber joints with slotted-in steel plates}

According to the observation of the experimental phenomena and the processing and analysis of the experimental results, the force-displacement relations of a single-bolted joint generally consist of five stages (Fig. 8): (1) the initial slip stage, which is mostly caused by installation errors and the gap between the bolt and the wall of the bolt hole in the timber and has no strong regularity for different specimens; (2) the linear stage, for which although an ideal straight line segment does not exist, the data points in the experiment have a high linear correlation and can be approximately fitted with a straight line; (3) the stiffness degradation stage, for which the plastic deformation of the timber continues to increase, some bolts encounter bending yield, the specimen stiffness decreases, and the curve reaches the yield plateau; (4) the yield plateau stage, in which the bearing capacity of the specimen reaches the peak value and is then maintained at this level or at a slightly lower level, the timber gradually reaches the plastic deformation limit, plastic hinges appear in the bolt, and the specimens have a certain ductility; and (5) and the failure stage, in which due to the occurrence of timber splitting or bolt fracture, the load sharply decreases, and the specimen fails.

According to the knowledge and understanding of the process-wide force-displacement relations of a singlebolted joint and in combination with the curve fitting and parameter identification, we constructed an empirical model of a single-bolted joint, and the mathematical formula is given in formula (1). This mechanical model has two parameters, for which the model curve is shown in Fig. 9 , where $P_{\mathrm{p}}$ is the bearing capacity of the bolted joint and $k_{\mathrm{e}}$ is the elastic stiffness of the bolted joint.

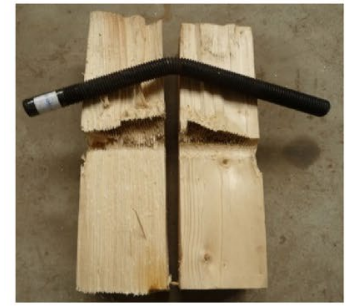

a Pattern I (S-12-105)

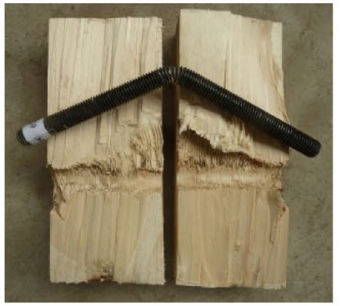

b Pattern III (S-14-180)

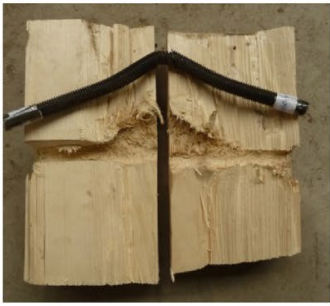

c Pattern IV (S-14-230)

Fig. 5 Joint failure patterns 

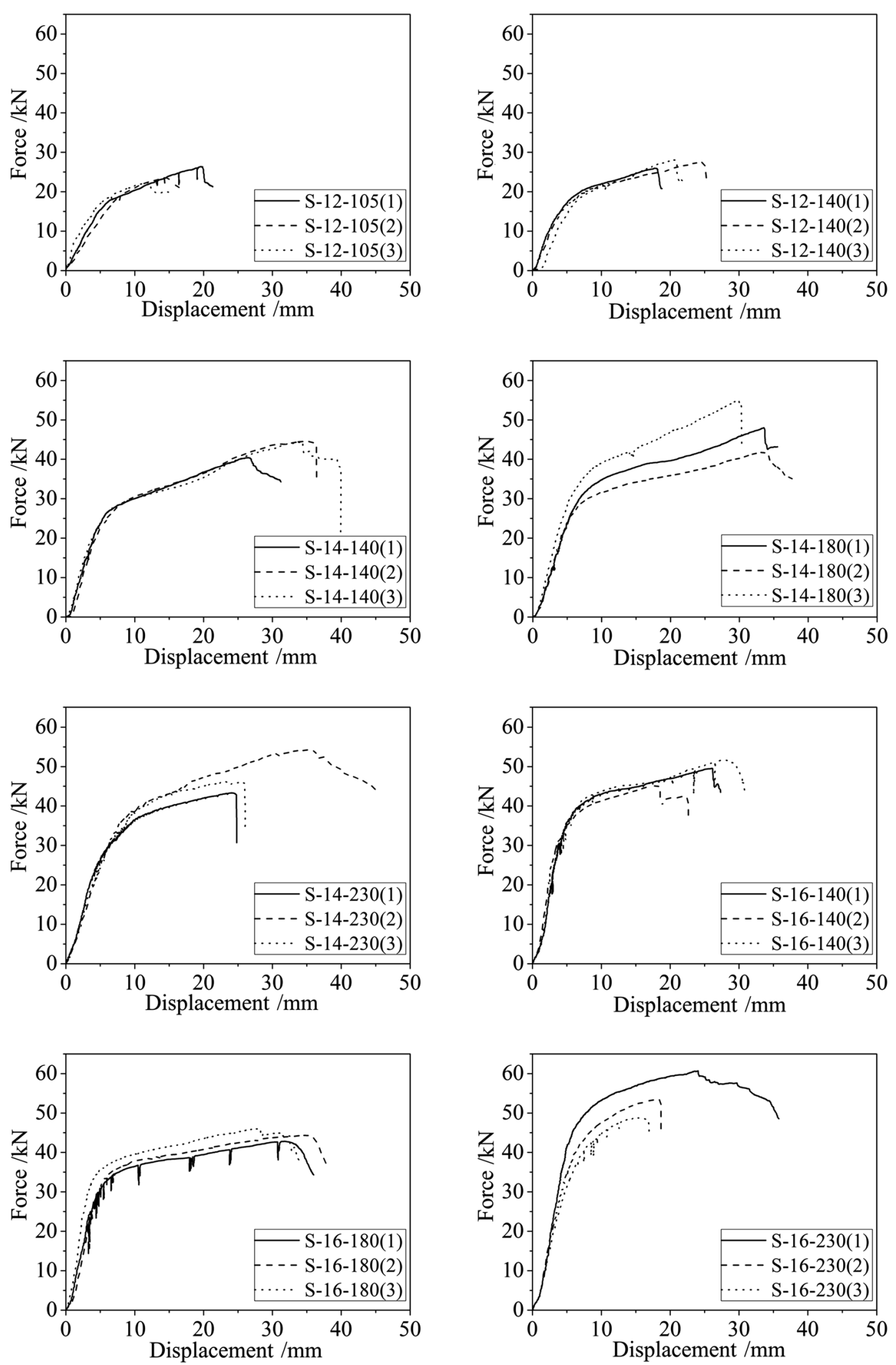

Fig. 6 Force-displacement curves of the specimens 


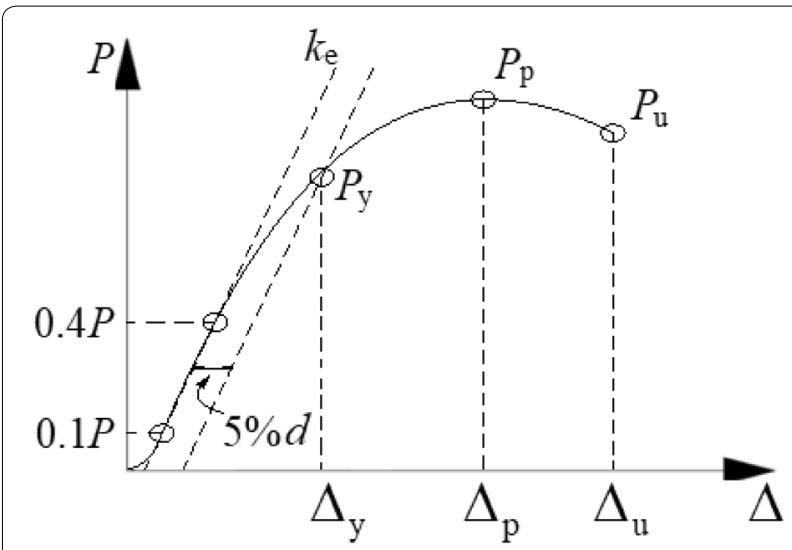

Fig. 7 Definitions of the main mechanical property parameters

Table 3 Main mechanical property parameters

\begin{tabular}{lcccc}
\hline Specimen series & $\boldsymbol{P}_{\mathbf{p}} / \mathbf{k N}$ & $\boldsymbol{k}_{\mathbf{e}} /(\mathbf{k N} / \mathbf{m m})$ & $\boldsymbol{\Delta}_{\mathbf{u}} / \mathbf{m m}$ & $\boldsymbol{D}$ \\
\hline S-12-105 & 24.14 & 3.81 & 17.97 & 3.90 \\
S-12-140 & 27.17 & 4.28 & 22.02 & 5.25 \\
S-14-140 & 43.16 & 5.94 & 35.82 & 8.00 \\
S-14-180 & 48.25 & 6.14 & 34.62 & 6.65 \\
S-14-230 & 47.91 & 5.88 & 32.18 & 5.65 \\
S-16-140 & 48.76 & 10.45 & 26.93 & 7.68 \\
S-16-180 & 44.42 & 9.18 & 36.27 & 9.71 \\
S-16-230 & 54.26 & 9.18 & 23.80 & 5.18 \\
\hline
\end{tabular}

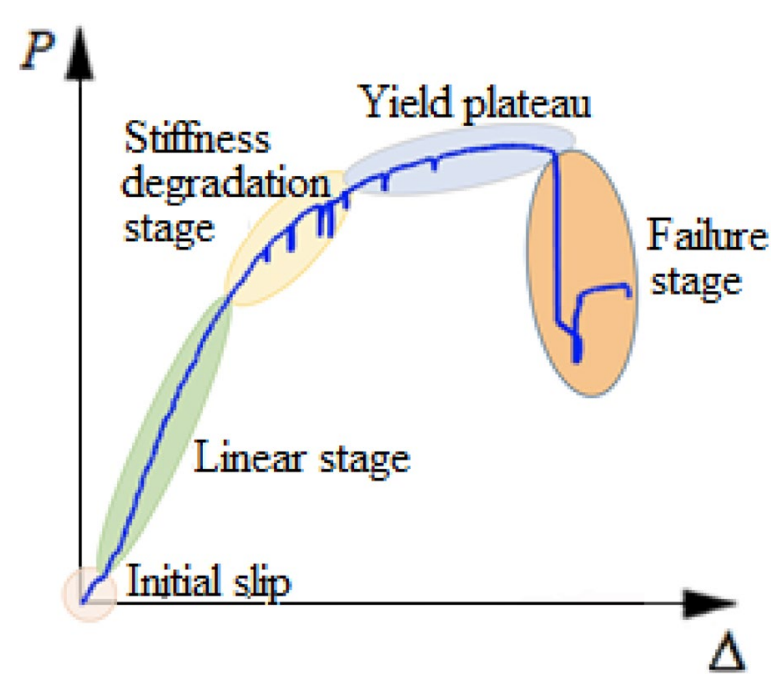

Fig. 8 Schematic for the process-wide force-displacement of a bolted joint

$$
P=P_{p}\left[1-\exp \left(-\frac{k_{\mathrm{e}}}{P_{p}} \Delta\right)\right] .
$$

It is worth noting that this mechanical model cannot provide the descending segment of the force-displacement curve, and subsequent efforts are still required. In timber engineering, the structure and the joints are rather flexible, mostly with a large displacement before failure. For this proposed model, a limited range of displacement is recommended if termination of the design or analysis is necessary.

\section{Theoretical analysis of the bearing capacity and elastic stiffness of bolted timber joints with slotted-in steel plates}

Bearing capacity

Presently, the mainstream theory for calculating the bearing performance of a bolted joint in timber engineering is the EYM, which assumes that the external force undertaken by the joint is the yield force $P_{\mathrm{y}}$ when the timber reaches the dowel bearing yield strength $f_{\mathrm{e}, \mathrm{y}}$ or the bolt reaches the yield moment $M_{\mathrm{y}}$. Scholars $[6,17]$ also used the dowel bearing ultimate strength of wood $f_{\mathrm{e}, \mathrm{u}}$ and the ultimate moment of the bolt $M_{\mathrm{u}}$ to calculate the bearing capacity of the bolted joint $P_{\mathrm{p}}$ by the yield theory. This section presents the following assumptions: (1) the force-displacement relations for the dowel bearing behavior of wood are ideal elastoplasticity; and (2) when the full length of the timber or the timber segment between two plastic hinges reaches the dowel bearing ultimate strength of the wood, the load is the bearing capacity of the bolted joint. The parameters include the bolt diameter $d$, the timber specimen thickness $l$, the ultimate bending moment for the bolt section $M_{\mathrm{u}}$ and the dowel bearing ultimate strength of the $\operatorname{wood} f_{\mathrm{e}, \mathrm{u}}$.

The free body diagrams in the ultimate state for three failure patterns are given in Fig. 10.

The equation of equilibrium for Pattern I is as follows:

$$
\frac{P_{\mathrm{p}}}{2}=f_{\mathrm{e}, \mathrm{u}} \cdot d \cdot \frac{l}{2} .
$$

The equations of equilibrium for Pattern III are as follows:

$$
\begin{aligned}
& \frac{P_{\mathrm{p}}}{2}+f_{\mathrm{e}, \mathrm{u}} \cdot d \cdot a=f_{\mathrm{e}, \mathrm{u}} \cdot d\left(\frac{1}{2} l-a\right), \\
& M_{\mathrm{u}}+f_{\mathrm{e}, \mathrm{u}} \cdot d \cdot a\left(\frac{1}{2} l-\frac{1}{2} a\right)=\frac{1}{2} f_{\mathrm{e}, \mathrm{u}} \cdot d\left(\frac{1}{2} l-a\right)^{2} .
\end{aligned}
$$

The equations of equilibrium for Pattern IV are as follows: 


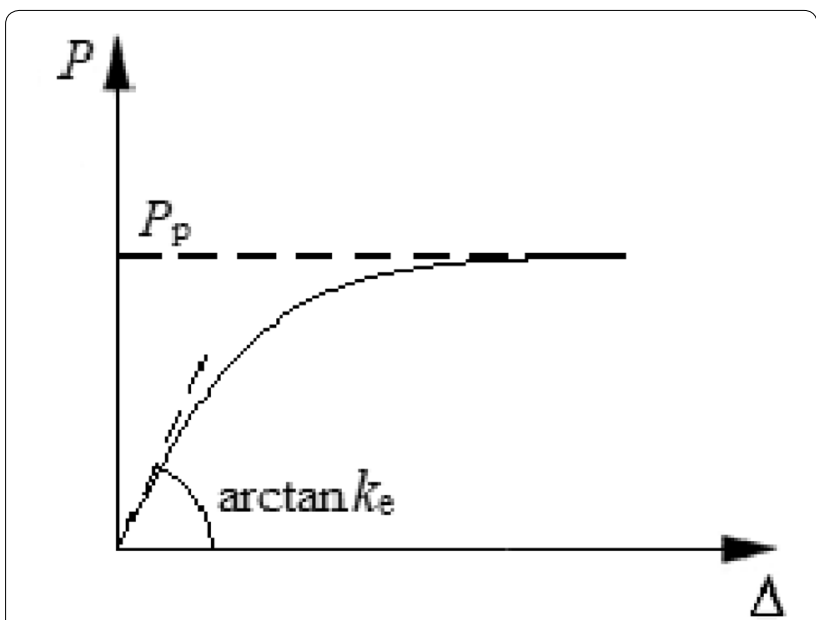

Fig. 9 Schematics of the mechanical model

$$
\begin{aligned}
& \frac{P_{\mathrm{p}}}{2}=f_{\mathrm{e}, \mathrm{u}} \cdot d \cdot b, \\
& 2 M_{\mathrm{u}}=\frac{1}{2} f_{\mathrm{e}, \mathrm{u}} \cdot d \cdot b^{2} .
\end{aligned}
$$

Solving Eqs. (2)-(6), we can express the bearing capacity of the joint as follows:

$$
\left\{\begin{array}{l}
P_{\mathrm{p}}=f_{\mathrm{e}, \mathrm{u}} \cdot d \cdot l(\text { Pattern } \mathrm{I}) \\
P_{\mathrm{p}}=f_{\mathrm{e}, \mathrm{u}} \cdot d \cdot l\left(\sqrt{2+\frac{16 M_{\mathrm{u}}}{f_{\mathrm{e}, \mathrm{u}} \cdot d \cdot l^{2}}}-1\right)(\text { Pattern III) } . \\
P_{\mathrm{p}}=4 \sqrt{M_{\mathrm{u}} \cdot f_{\mathrm{e}, \mathrm{u}} \cdot d}(\text { Pattern IV })
\end{array}\right.
$$

\section{Elastic stiffness}

The elastic stiffness is analyzed by supposing that (1) the contact relation between the bolt and the timber is a EulerBernoulli beam acting on an elastic foundation [18, 19]; (2) the contact stiffness of the points on the elastic foundation is taken as the dowel bearing stiffness of the wood; and (3) the constraint influence of the nut and washer is not considered. The parameters include the modulus of elasticity of the steel bolt $E$ and the dowel bearing stiffness of the wood $k_{\mathrm{s}}$.

Because single-bolted joints are bilaterally symmetric (Fig. 11a), only the right portion is analyzed. The positive directions of the $x$ and $w$ axes and the position of the origin are shown in Fig. 11b. The free body diagram for a bolt microelement at any $x$ is shown in Fig. 11c.

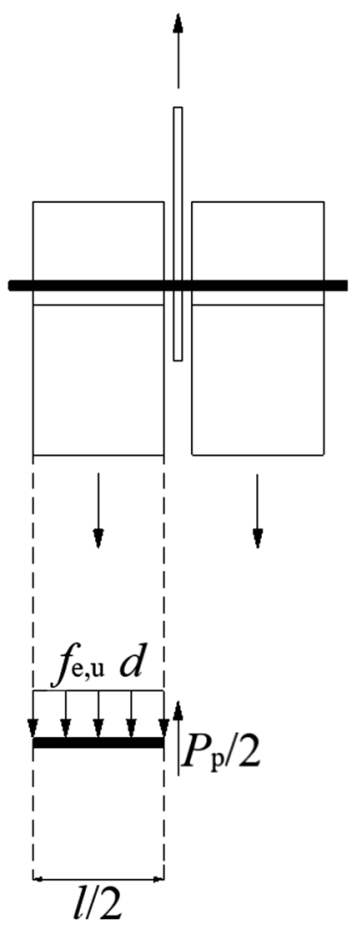

a Pattern I

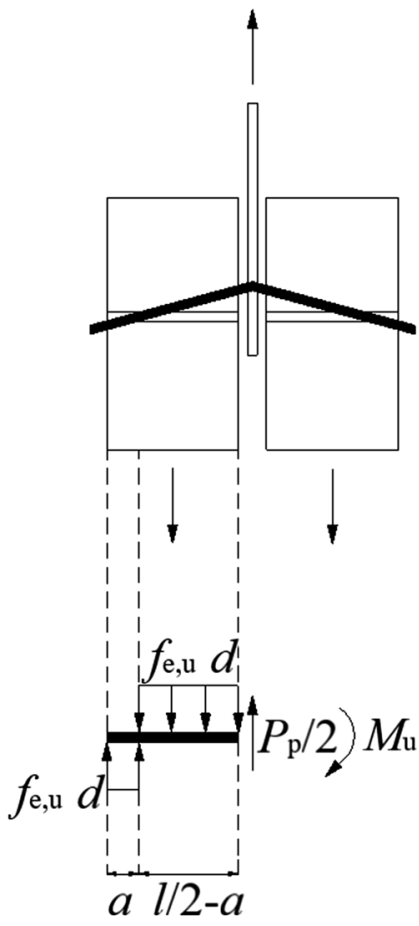

b Pattern III

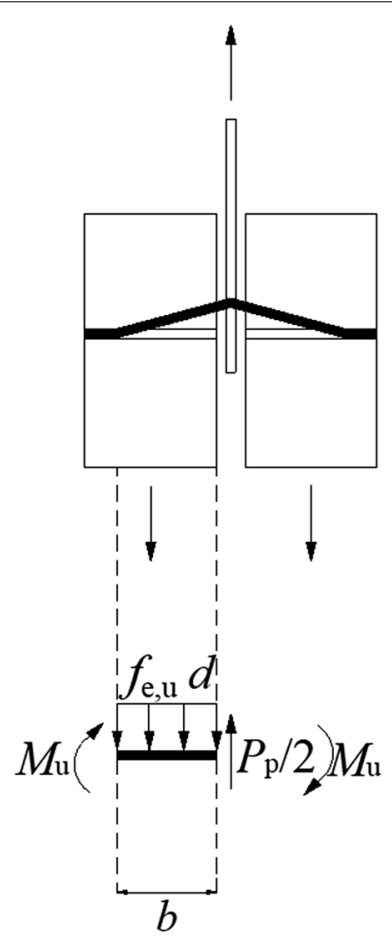

c Pattern IV

Fig. 10 Free body diagrams of the joint in the limit state 
From the force balance in the $w$-axis direction, we have

$$
V-k_{\mathrm{s}} w(x) \mathrm{d} x-(V+\mathrm{d} V)=0 .
$$

Hence,

$$
\frac{\mathrm{d} V}{\mathrm{~d} x}+k_{\mathrm{s}} w(x)=0 .
$$

The relations for the shear force, bending moment, and curvature of the Euler-Bernoulli beam are as follows:

$$
\begin{aligned}
& V=\frac{\mathrm{d} M}{\mathrm{~d} x}, \\
& M=E I \frac{\mathrm{d}^{2} w(x)}{\mathrm{d} x^{2}} .
\end{aligned}
$$

From formulas (9)-(11), we have the following:

$$
\frac{\mathrm{d}^{4} w(x)}{\mathrm{d} x^{4}}+\frac{k_{\mathrm{s}}}{E I} w(x)=0 .
$$

With $l_{\mathrm{c}}=\sqrt[4]{\frac{4 E I}{k_{\mathrm{s}}}}$ and $\xi=\frac{x}{l_{\mathrm{c}}}$, we obtain the following equation:

$$
\frac{1}{l_{\mathrm{c}}^{4}} \frac{\mathrm{d}^{4} w(\xi)}{\mathrm{d} \xi^{4}}+\frac{4}{l_{\mathrm{c}}^{4}} w(\xi)=0 .
$$

Hence,

$$
\frac{\mathrm{d}^{4} w(\xi)}{\mathrm{d} \xi^{4}}+4 w(\xi)=0 .
$$

This homogeneous differential equation is then solved, and the general solution is expressed below:

$$
\begin{aligned}
w(\xi)= & A_{1} e^{\xi}(\cos \xi+i \sin \xi)+A_{2} e^{\xi}(\cos \xi-i \sin \xi) \\
& +A_{3} e^{-\xi}(\cos \xi+i \sin \xi)+A_{4} e^{-\xi}(\cos \xi-i \sin \xi)
\end{aligned}
$$

In formula (15), $A_{1}, A_{2}, A_{3}$, and $A_{4}$ are constants. With $B_{1}=A_{1}+A_{2}, B_{2}=A_{1} i-A_{2} i, B_{3}=A_{3}+A_{4}$ and $B_{4}=A_{3} i-A_{4} i$, we obtain the following formula:

$$
w(\xi)=B_{1} e^{\xi} \cos \xi+B_{2} e^{\xi} \sin \xi+B_{3} e^{-\xi} \cos \xi+B_{4} e^{-\xi} \sin \xi .
$$

As $x$ (namely, $\xi$ ) increases, the deflection $w$ gradually approaches 0 , while in formula (16), the terms containing $e^{\xi} \cos \xi$ and $e^{\xi} \sin \xi$ diverge as $x$ increases; thus, $B_{1}=B_{2}=0$.

With $g_{1}=e^{-\xi} \cos \xi, g_{2}=e^{-\xi} \sin \xi, g_{3}=g_{1}+g_{2}$, and $g_{4}=g_{1}-g_{2}$, we have $\frac{\mathrm{d} g_{1}}{\mathrm{~d} \xi}=-g_{3}, \frac{\mathrm{d} g_{2}}{\mathrm{~d} \xi}=g_{4}, \frac{\mathrm{d} g_{3}}{\mathrm{~d} \xi}=-2 g_{2}$, and $\frac{\mathrm{d} g_{4}}{\mathrm{~d} \xi}=-2 g_{1}$. Therefore, the deflection $w$, angle of rotation $\theta$, bending moment $M$, and shear force $V$ at any $x$ are expressed as follows:

$$
\begin{aligned}
& w(\xi)=B_{3} g_{1}+B_{4} g_{2} \\
& \theta(\xi)=\frac{\mathrm{d} w(x)}{\mathrm{d} x}=\frac{1}{l_{\mathrm{c}}}\left(-B_{3} g_{3}+B_{4} g_{4}\right) \\
& M(\xi)=E I \frac{\mathrm{d}^{2} w(x)}{\mathrm{d} x^{2}}=\frac{2 E I}{l_{\mathrm{c}}^{2}}\left(B_{3} g_{2}-B_{4} g_{1}\right), \\
& V(\xi)=\frac{\mathrm{d} M(x)}{\mathrm{d} x}=\frac{2 E I}{l_{\mathrm{c}}^{3}}\left(B_{3} g_{4}+B_{4} g_{3}\right) .
\end{aligned}
$$

At $x=0$ (namely, $\xi=0$ ), the shear force $V_{0}$ and bending moment $M_{0}$ (Fig. 12b) can be substituted into formulas (19) and (20) to obtain the following formulas:

$$
\begin{aligned}
& B_{3}=\frac{l_{\mathrm{c}}}{2 E I}\left(l_{\mathrm{c}} V_{0}+M_{0}\right), \\
& B_{4}=-\frac{l_{\mathrm{c}}}{2 E I} M_{0} .
\end{aligned}
$$

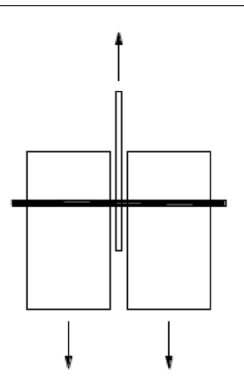

a The bolted joint

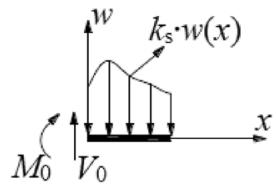

b A half bolt

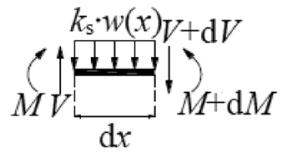

c A bolt microelement

Fig. 11 Free body diagrams of a bolt 
Thus, formulas (17)-(20) can be expressed as follows:

$$
\begin{aligned}
& w=\frac{l_{\mathrm{c}}^{2}}{2 E I}\left(l_{\mathrm{c}} V_{0} g_{1}+M_{0} g_{4}\right), \\
& \theta=-\frac{l_{\mathrm{c}}}{2 E I}\left(l_{\mathrm{c}} V_{0} g_{3}+2 M_{0} g_{1}\right), \\
& M=l_{\mathrm{c}} V_{0} g_{2}+M_{0} g_{3}, \\
& V=V_{0} g_{4}-\frac{2}{l_{\mathrm{c}}} M_{0} g_{2} .
\end{aligned}
$$

The elastic stiffness $k_{\mathrm{e}}$ of the bolted joint is described as the proportional relation of the external force $P$ with the displacement $\Delta$ of the midpoint of the bolt. $\Delta$ is composed of the deflection of the bolt on the timber foundation and the deflection of the bolt on the steel plate foundation. Because the deflection of the bolt on the steel plate foundation is far smaller than the deflection of the bolt on the timber foundation and may thus be negligible, $\Delta$ may be approximately considered to be $\Delta \approx w_{0}$.

At $x=0$ (namely, $\xi=0$ ), the shear force $V_{0}=\frac{1}{2} P$ is plugged into formula (23), and thus,

$$
\Delta=w_{0}=\frac{l_{\mathrm{c}}^{2}}{2 E I}\left(l_{\mathrm{c}} \frac{P}{2}+M_{0}\right) .
$$

Assuming that

$$
\alpha=\frac{M_{0}}{l_{\mathrm{c}} P}
$$

where $\alpha$ is a constant, the following formula can be obtained:

$$
P=\frac{1}{(1+2 \alpha)} \frac{4 E I}{l_{\mathrm{c}}^{3}} \Delta .
$$

Let

$$
\beta=\frac{1}{(1+2 \alpha)},
$$

where $\beta$ is a constant. Substituting $l_{\mathrm{c}}=\sqrt[4]{\frac{4 E I}{k_{\mathrm{s}}}}$ into formula (29) yields

$$
P=\beta\left(k_{\mathrm{s}} \sqrt[4]{\frac{4 E I}{k_{\mathrm{s}}}}\right) \Delta .
$$

Thus, the elastic stiffness $k_{\mathrm{e}}$ of the bolted joint satisfies the following formula:

\section{Table 4 Parameter values}

\begin{tabular}{llll}
\hline $\begin{array}{l}\text { Modulus } \\
\text { of elasticity } \\
\text { E/MPa }\end{array}$ & $\begin{array}{l}\text { Ultimate } \\
\text { bending } \\
\text { moment } \\
\boldsymbol{M}_{\mathbf{u}} / \mathrm{Nmm}\end{array}$ & $\begin{array}{l}\text { Dowel bearing } \\
\text { ultimate } \\
\text { strength } \\
\boldsymbol{f}_{\mathbf{e}, \mathbf{u}} /\left(\mathbf{N} / \mathbf{m m}^{2}\right)\end{array}$ & $\begin{array}{l}\text { Dowel bearing } \\
\text { stiffness } \\
\boldsymbol{k}_{\mathbf{s}} /\left(\mathrm{N} / \mathbf{m m}^{2}\right)\end{array}$ \\
\hline $2.06 \times 10^{5}$ & $4.37 \times 10^{5}$ & 24.03 & 62.33 \\
\hline
\end{tabular}

Table 5 Theoretical calculation values of the bearing capacity and elastic stiffness

\begin{tabular}{lll}
\hline Specimen series & $\boldsymbol{P}_{\mathbf{p}} / \mathbf{k N}$ & $\boldsymbol{k}_{\mathbf{e}} /(\mathbf{k N} / \mathbf{m m})$ \\
\hline S-16-140 & 53.83 & 10.06 \\
S-16-180 & 41.55 & 10.06 \\
S-16-230 & 51.84 & 10.06 \\
\hline
\end{tabular}
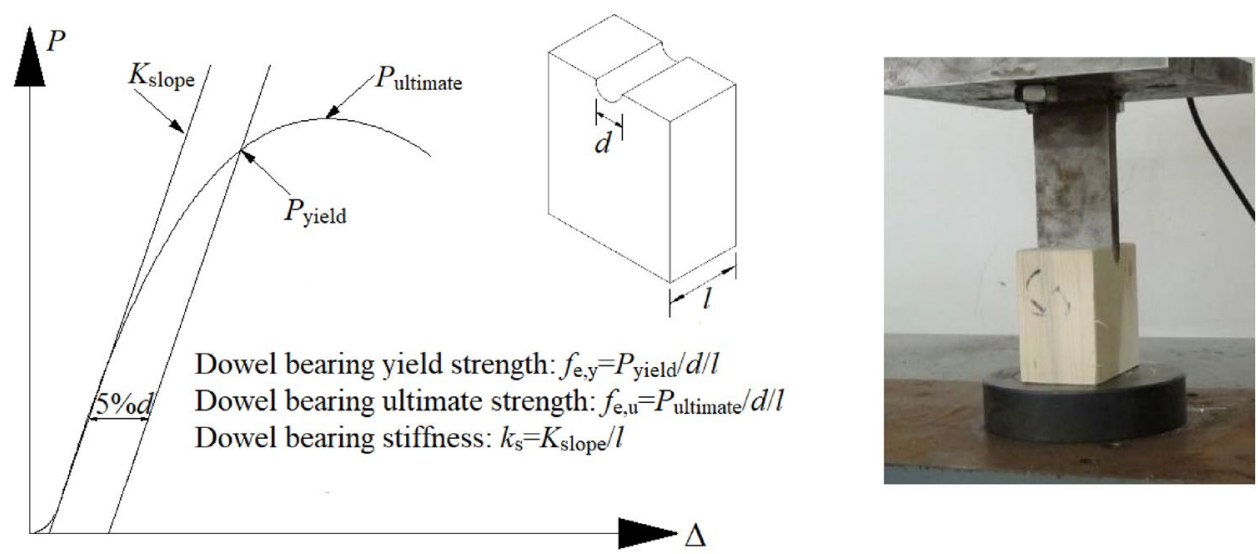

Fig. 12 Dowel bearing test of the wood 

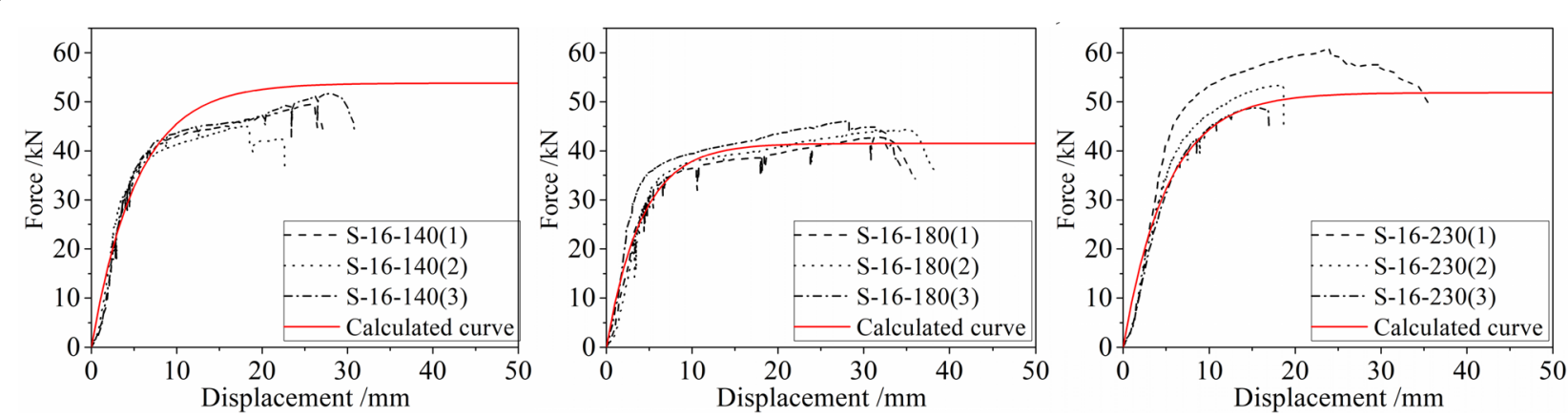

Fig. 13 Comparison of calculated curves and experimental curves

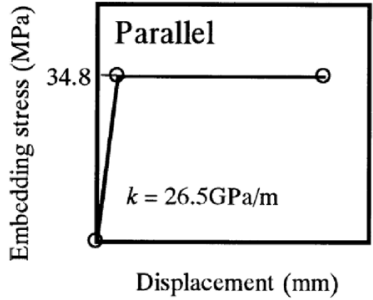

a Dowel bearing properties of wood

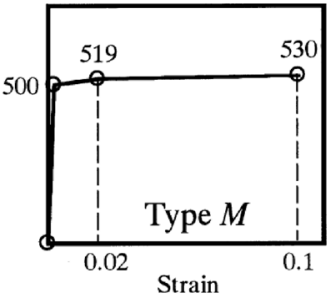

b Stress-strain relationship of steel bolts

Fig. 14 Material properties from the literature [6]
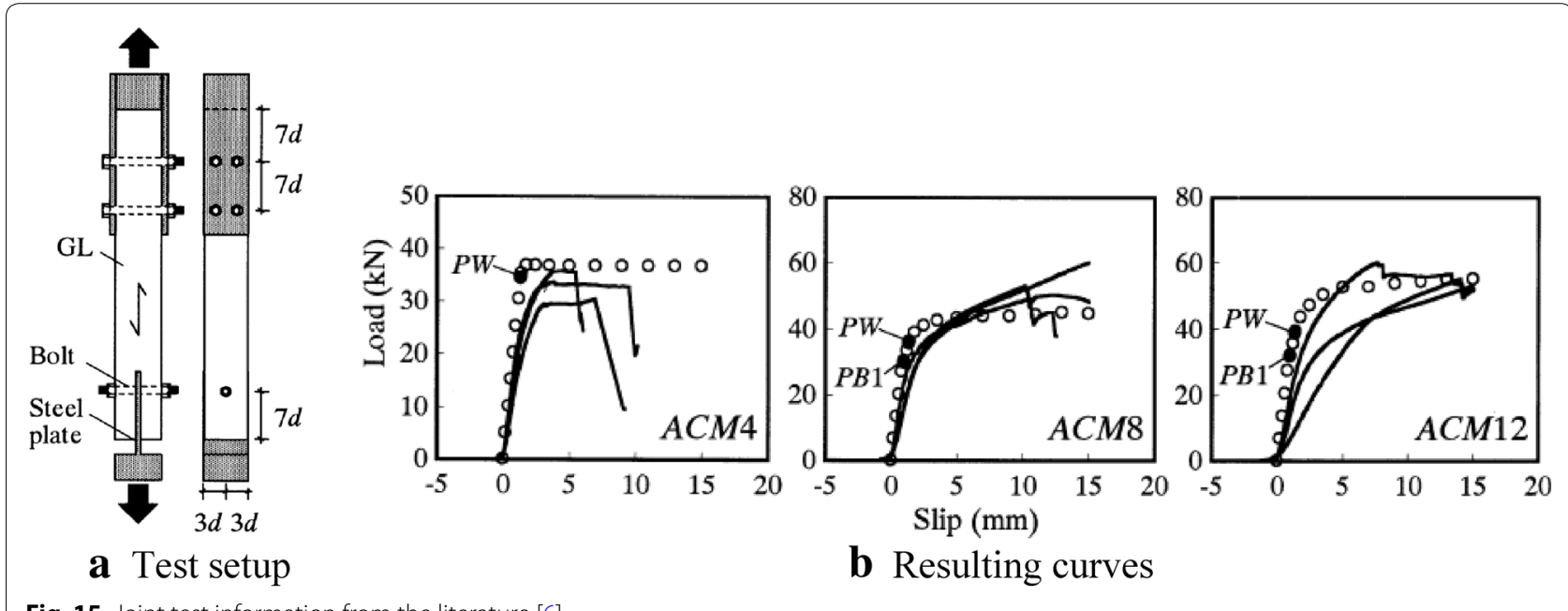

b Resulting curves

Fig. 15 Joint test information from the literature [6]

$$
k_{\mathrm{e}}=\frac{P}{\Delta}=\beta\left(k_{\mathrm{s}} \sqrt[4]{\frac{4 E I}{k_{\mathrm{s}}}}\right),
$$

where $k_{\mathrm{s}}$ and $E I$ are determined by the material properties and geometries of the timber and the bolt. $\beta$ is discussed as follows: (1) When the rotation of the bolt midpoint $(x=0)$ is fully constrained $\left(\theta_{0}=0\right)$, we substitute $\theta_{0}=0$ into formulas (24), (28), and (30) and solve them to obtain $\beta=2$; (2) when the rotation of the bolt midpoint $(x=0)$ is not fully constrained $\left(M_{0}=0\right)$, we 

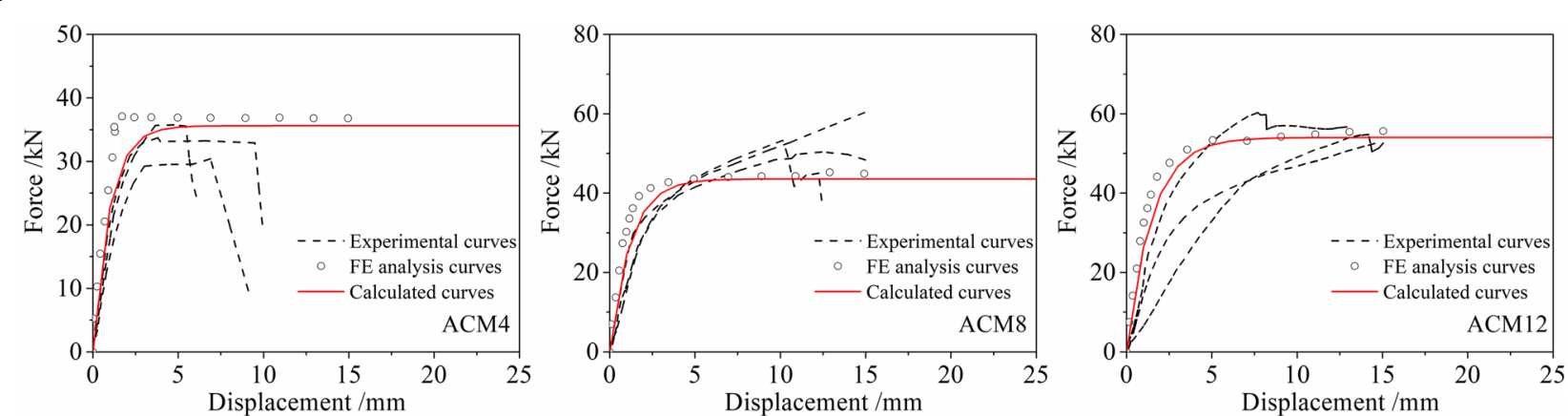

Fig. 16 Comparison of the calculated curves, experimental curves, and finite element (FE) analysis curves

Table 6 Theoretical calculation values of the bearing capacity and elastic stiffness from the literature [6]

\begin{tabular}{lll}
\hline Specimen series & $\boldsymbol{P}_{\mathbf{p}} / \mathbf{k N}$ & $\boldsymbol{k}_{\mathbf{e}} /(\mathbf{k N} / \mathbf{m m})$ \\
\hline ACM4 & 35.64 & 36.08 \\
ACM8 & 43.62 & 36.08 \\
ACM12 & 54.02 & 36.08 \\
\hline
\end{tabular}

substitute $M_{0}=0$ into formulas (28) and (30) and solve them to obtain $\beta=1$; thus, $\beta$ is in the range of 1 to 2 . In the elastic stage of loading of the bolted joint with a slotted-in steel plate, the rotation at the midpoint of the bolt is small, and $\beta$ can be taken as approximately 2 .

\section{Calculation of force-displacement relations for bolted timber joints with slotted-in steel plates}

Based on the two-parameter mechanical model and the theoretical formula of the bearing capacity $P_{\mathrm{p}}$ and elastic stiffness $k_{\mathrm{e}}$ proposed in this paper, the specimen group with a diameter of $16 \mathrm{~mm}$ (that is, specimens S-16-140, S-16-80, and S-16-230) is taken as an example for calculating the force-displacement relations of the joints for comparison with the experimental results so that the rationality of the theoretical formula and the practicability of the mechanical model can be verified.

\section{Material property parameters}

In the theoretical calculation of the bearing capacity $P_{\mathrm{p}}$ and elastic stiffness $k_{\mathrm{e}}$, the parameters include the bolt diameter $d$, the bolt steel modulus of elasticity $E$, the ultimate bending moment $M_{\mathrm{u}}$ for the plastic limit of the bolt section, the timber specimen thickness $l$, the dowel bearing ultimate strength of wood $f_{\mathrm{e}, \mathrm{u}}$, and the dowel bearing stiffness of wood $k_{\mathrm{s}}$. A material property test of the 16-mm-diameter bolt and a dowel bearing test of the wood [20] (Fig. 12) were performed to determine the related parameters (Table 4). In the dowel bearing test of the wood, a $5 \%$ diameter method was used to determine the yield point. The mean values were obtained from the tests for the subsequent calculation.

\section{Calculation of bearing capacity and elastic stiffness}

According to the experimental phenomena, the specimens S-16-140, S-16-180, and S-16-230 corresponded to failure Patterns I, III, and IV, respectively, and the material property parameters were substituted into formulas (7) and (32) to obtain the bearing capacity and elastic stiffness of the specimens (Table 5). During the calculation of the bearing capacity in the design, the failure pattern can be determined through the slenderness of the specimen or the minimum values in three failure patterns.

\section{Determination of force-displacement curves}

By substituting the data in Table 5 into formula (1), we can obtain the calculated force-displacement curve of each specimen for comparison with the experimental curve, as shown in Fig. 13.

Figure 13 shows that the calculated curve can predict the experimental curve well. In practice, the related parameters can be determined by performing a relatively small material property test, and the process-wide forcedisplacement relations of the bolted timber joints with slotted-in steel plates can be calculated in combination with the calculation formulas of the bearing capacity and elastic stiffness and the two-parameter mechanical model proposed in this paper.

\section{Validation of the methodology with data from the literature}

To further validate the methodology proposed in this paper, data, including material properties and joint force-displacement curves, were collected from the literature [6]. The dowel bearing properties of wood and the stress-strain relationship of steel bolts are shown in Fig. 14. The joint test setup and the resulting curves are shown in Fig. 15. 
Based on the literature, the parameters are expressed as follows: the bolt diameter $d=16 \mathrm{~mm}$, the timber specimen thickness $l=64 \mathrm{~mm}$ for the ACM4 series $(l / d=4)$, the timber specimen thickness $l=128 \mathrm{~mm}$ for the ACM8 series $(l / d=8)$, and the timber specimen thickness $l=192 \mathrm{~mm}$ for the ACM12 series $(l / d=12)$. From Fig. 14a, the dowel bearing ultimate strength of wood $f_{\mathrm{e}, \mathrm{u}}$ is calibrated as $34.8 \mathrm{~N} / \mathrm{mm}^{2}$, and the dowel bearing stiffness of wood $k_{\mathrm{s}}$ is calibrated as $26.5 \mathrm{GPa} / \mathrm{m} \times 16 \mathrm{~mm}=424 \mathrm{~N} / \mathrm{mm}^{2}$. From Fig. $14 \mathrm{~b}$, the modulus of elasticity $E$ of the steel bolt is calibrated as $1.08 \times 10^{5} \mathrm{MPa}$, and the ultimate bending moment $M_{\mathrm{u}}$ of the steel bolt is calibrated as $1 / 6 \times(16 \mathrm{~mm})^{3} \times 500 \mathrm{MPa}$ $=341 \mathrm{Nm}$ (in the literature, $M_{\mathrm{u}}=348 \mathrm{Nm}$ ).

According to the literature, the specimen series ACM4, ACM8, and ACM12 corresponded to failure Patterns I, III, and III, respectively. By substituting the acquired data into formulas (7) and (32), the bearing capacity and elastic stiffness were obtained (Table 6). Then, formula (1) was used to plot the force-displacement curves shown in Fig. 15b for comparison (Fig. 16).

In Fig. 16, the experimental curves and the FE (finite element) analysis curves were taken from the literature (shown in Fig. 15b), while the calculated curves were obtained by applying the methodology proposed in this paper. The calculated curves and the FE analysis curves show good agreement because the input data are the same for both the FE analysis and the theoretical calculation. It can be concluded that the $\mathrm{FE}$ analysis from the literature verifies the proposed methodology. In addition, the calculated curves can predict the force-displacement relations of the bolted timber joint reasonably well with the experimental curves, and the accuracy is acceptable.

\section{Conclusions}

The force-displacement curves of bolted timber joints with slotted-in steel plates consisted of a linear stage, a stiffness degradation stage, a yield plateau stage, and a failure stage. Some specimens exhibited initial slip, which was caused by installation errors and the gap between the bolt and the wall of the bolt hole in the timber. The joints showed a high deformation capacity and a good ductility.

The bearing capacity of the specimen was jointly influenced by the bolt diameter $d$ and the specimen thickness $l$. As the bolt diameter $d$ or the specimen thickness $l$ increased, the bearing capacity of the specimen increased. As the specimen slenderness $l / d$ increased, the specimen failure pattern changed from Pattern I to Pattern III and then to Pattern IV. The elastic stiffness of the specimen mainly depended on the bolt diameter $d$, and as the bolt diameter $d$ increased, the elastic stiffness increased. For the specimens with the same bolt diameter $d$, changing the timber thickness $l$ only slightly influenced the joint stiffness.

The force-displacement curves of the bolted timber joints with slotted-in steel plates can be expressed with a two-parameter mechanical model of the bearing capacity and elastic stiffness. Then, theoretical calculation formulas for the bearing capacity and elastic stiffness of the joints were derived. The process-wide force-displacement relations of the bolted timber joints with slottedin steel plates can be calculated in combination with the calculation formulas of the bearing capacity and elastic stiffness and the two-parameter mechanical model proposed in this paper.

In future work, the formulas for the dowel bearing properties (i.e., strength and stiffness) of wood should be developed to fill the gap, and the model should be upgraded so that it can be applied to joints with multiple fasteners.

\section{Abbreviations}

EYM: European yield model; NDS: National design specifications; FE: Finite element.

\section{Acknowledgements}

The authors acknowledge the help of the School of Civil Engineering of Zhengzhou University.

\section{Authors' contributions}

YL analyzed the experimental data and drafted the manuscript. YW performed the experiments. $Y Z, M C$, and $X N$ verified the proposed methodology from the literature. All the authors read and approved the final manuscript.

\section{Funding}

The work in this paper is financially supported by the China Postdoctoral Science Foundation Grant (Grant No. 2018M632804), the Postdoctoral Research Grant in Henan Province (Grant No. 001702034), and the Students'Innovation and Entrepreneurship Training Program of Zhengzhou University (Grant No. 201910459091 and Grant No. 2020cxcy223).

\section{Availability of data and materials}

Most data analyzed during this study are included in this published article. Supplementary information is available from the corresponding author on reasonable request.

\section{Competing interests}

The authors declare that they have no competing interests.

Received: 9 Auqust 2020 Accepted: 26 November 2020

Published online: 07 December 2020

\section{References}

1. Johansen KW (1949) Theory of timber connections. Int Assoc Bridge Struct Eng 9:249-262

2. NDS (2015) National design specification for wood construction. American Wood Council, Washington DC

3. CSA O86 (2009) Canadian Standards Association Standard O86: engineering design in wood. Canadian Standards Association, Toronto

4. Eurocode 5 (2004) Eurocode 5: design of timber structures. European Committee for Standardization, Brussels

5. Sawata K, Yasumura M (2002) Determination of embedding strength of wood for dowel-type fasteners. J Wood Sci 48:138-146 
6. Sawata K, Yasumura M (2003) Estimation of yield and ultimate strengths of bolted timber joints by nonlinear analysis and yield theory. J Wood Sci 49:383-391

7. Dorn M, Borst K, Eberhardsteiner J (2013) Experiments on dowel-type timber connections. Eng Struct 47:67-80

8. Jorissen A (1998) Double shear timber connections with dowel type fasteners. Ph.D. Thesis. Delft University of Technology, Delft, Netherlands

9. Xu B, Bouchair A, Racher P (2015) Mechanical behavior and modeling of dowelled steel-to-timber moment-resisting connections. J Struct Eng 141:04014165

10. Xiong HB, Liu YY (2016) Experimental study of the lateral resistance of bolted glulam timber post and beam structural systems. J Struct Eng 142:E4014002

11. Liu YY, Xiong HB (2018) Lateral performance of a semi-rigid timber frame structure: theoretical analysis and experimental study. J Wood Sci 64:591-600

12. Awaludin A (2005) Moment resistance analysis on various configuration of multiple-bolt timber connection using beam on elastic foundation theory and rigid plate assumption. Media Komunikasi Teknik Sipil 13:57-62

13. Awaludin A, Smittakorn W, Hayashikawa T, Hirai T (2007) M- $\theta$ curve of timber connection with various bolt arrangements under monotonic loading. J Struct Eng 53:853-862

14. Yasumura M, Kawai N (1998) Estimating seismic performance of woodframed structures. In: Proceedings of 1998 I.W.E.C., Switzerland, pp 564-571

15. Muñoz W, Salenikovich A, Mohammad M, Quenneville P (2008) Determination of yield point and ductility of timber assemblies: in search for a harmonised approach. In: Proceedings 2008 world conference on timber engineering, Japan, pp 1064-1071

16. ASTM D5652-95 (2013) Standard test methods for bolted connections in wood and wood-based products. American Society for Testing and Materials, West Conshohocken

17. Ottenhaus LM, Li MH, Smith T, Quenneville P (2016) Ductility and overstrength of dowelled LVL and CLT connections under cyclic loading. In: Proceedings 2016 world conference on timber engineering, Austria, pp $1-9$

18. Foschi RO (1974) Load-slip characteristics of nails Wood Sci 7:69-76

19. Foschi RO (1977) Load-slip characteristics for connections with common nails. Wood Sci 9:118-123

20. ASTM D5764-97a (2002) Standard test method for evaluating dowelbearing strength of wood and wood-based products. American Society for Testing and Materials, West Conshohocken

\section{Publisher's Note}

Springer Nature remains neutral with regard to jurisdictional claims in published maps and institutional affiliations.

\section{Submit your manuscript to a SpringerOpen ${ }^{\odot}$ journal and benefit from:}

- Convenient online submission

- Rigorous peer review

- Open access: articles freely available online

- High visibility within the field

- Retaining the copyright to your article

Submit your next manuscript at $\boldsymbol{\nabla}$ springeropen.com 